\title{
O PAPEL DOS INTELECTUAIS \\ NA AMÉRICA LATINA *
}

\author{
Elzimar Goettenauer de Marins Costa**
}

Resumo: $O$ intelectual detém um saber, ele possui conbecimentos que, ademais de babilitá-lo profissionalmente, podem capacitá-lo a exercer uma determinada função não necessariamente restrita à sua profissão. O desafio será sempre o de não perder de vista os valores - a ética - do papel que é convocado a desempenbar. Ética que deriva do respeito às necessidades essenciais do ser bumano: viver plena $e$ dignamente, em um ambiente onde não só esteja garantido o acesso às condiçōes materiais de existência, como também estejam asseguradas a liberdade e a justiça. Norteado por esses princípios, o intelectual na América Latina tem sido impelido a discutir, esclarecer e denunciar o que impede a plenitude da vida bumana.

"En todas las sociedades, la función del intelectual es navegar contra la corriente, cantar cuatro verdades $y$ seguir siendo incorruptible e insumiso cuando a su alrededor todos callan, se someten y se corrompen."

Tomás Eloy Martinez

- Recebido para publicação em novembro de 2004.

- Professora da Faculdade de Letras/UFMG. 
Abordar a questão relativa ao papel ou à função dos intelectuais no mundo atual é enveredar por uma trilha sinuosa, percorrida já por tantos pensadores, sabendo-se que o fim do percurso não será uma conclusão definitiva sobre o tema, mas apenas um conjunto talvez mal costurado de digressões. Além dos diversos estudos de autores famosos que tratam do assunto, há ainda outras tantas considerações dispersas em vários textos afins. A proposta do presente estudo é revisitar o tema à luz de outras leituras, pinçando de cada autor algumas de suas proposições e apresentando alguns comentários e questionamentos.

O primeiro passo de aproximação ao tema remete necessariamente à própria definição da palavra intelectual, ou, mais especificamente, remete às características da categoria a que o termo alude: quem são os intelectuais? Que aspectos ajudam a construir o seu perfil? Evidentemente, formular uma resposta para essas perguntas significa discorrer ao mesmo tempo sobre o que eles fazem - ou o que deveriam fazer.

Um segundo ponto para reflexão, desdobramento do anterior, é o que diz respeito ao modo pelo qual alguém adquire o status de intelectual: como ele ganha projeção? O que há no seu fazer, ou no seu dizer, que the permite ser reconhecido e nomeado como tal?

Depois dessas considerações mais ou menos gerais, podemos situar-nos em um tempo e um espaço mais determinados: que papel desempenha o intelectual hoje na América Latina? Neste tópico, farei um recorte para focalizar a contribuição dos intelectuais na construção de uma possível concepção de identidade latino-americana, tomando como referência um texto de Jorge Castañeda e uma breve revisão da atuação dos intelectuais em nosso continente ao longo de sua história, chegando as últimas décadas, quando as transformações ocorrem num ritmo acelerado, impulsionadas 
pela globalização, pela mídia e pela Internet, exigindo explicações e conceituações sob novas perspectivas.

\section{Quanto ao emprego da palavra intelectuais:}

Segundo Norberto Bobbio, a palavra associa-se ao vocábulo russo intelligentsia e designa um conjunto de pessoas que têm uma determinada função e desempenham um papel específico dentro da sociedade. Pode ter sido usada pela primeira vez pelo romancista Boborykin e foi difundida nas últimas décadas do século XIX (BOBBIO, 1997: 121-2). Não há uma definição precisa do termo, mas há em torno de sua conceituação uma gama de elucubrações, pois, como afirma Edward Said, cada região produziu seus próprios intelectuais e cada um desses agrupamentos discutiu seu próprio engendramento, justificandose com "ardente paixão" (SAID, 1996: 29); além disso, vários pensadores (filósofos, sociólogos, historiadores, escritores, entre outros), ao longo do século $\mathrm{XX}$, acentuaram matizes diferentes ao abordar questões relativas ao tema.

Uma de suas acepções, entretanto, consolidada em função do caso Dreyfus e o conseqüente "Manifeste des intellectuales" (1898), resiste até o presente e se refere a "um grupo de homens", normalmente literatos, que se manifestam publicamente contra o poder político em nome de uma verdade da qual se consideram os depositários. É nesse sentido que o filósofo francês contemporâneo Bernard-Henri Lévy afirma que o intelectual é "um animal sobretudo moderno", pois embora sempre tenha havido escritores e artistas, não houve sempre artistas ou escritores "saindo de sua disciplina para, sem a sombra de um mandato, e fortalecidos por uma autoridade adquirida em outra parte, achar ao mesmo tempo natural e útil vir misturar sua voz aos grandes debates da cidade" (LÉVY, 1998: 26). 
Em torno dessa matriz básica há também uma tipologia dos intelectuais que varia segundo a concepção de quem os analisa, devendo-se obviamente levar em consideração as épocas, os lugares e os ângulos a partir dos quais foram formuladas, embora essas circunstâncias não sejam aprofundadas aqui.

Para Julien Benda, o "autệntico" intelectual é aquele cuja atividade não é guiada por objetivos práticos ou materiais, suas ações são movidas por princípios de justiça e verdade; torna-se um "traidor", um "falso" intelectual quando se envolve com questões de classe, raça ou nação.

Segundo Gramsci, há um tipo tradicional de intelectual constituído pelo literató, pelo filosófo, pelo artista. O novo intelectual é aquele que se insere na vida prática, formado historicamente, de um modo "orgânico", em conexão com grupos sociais, principalmente os mais importantes; é uma espécie de "funcionário" das superestruturas, "comissário" do grupo dominante, atuando nas funções subalternas da hegemonia social e do governo político.

Sartre distingue o técnico do saber prático, potencialmente intelectual - agente de um particularismo ideológico, fazendo passar por leis científicas o que de fato é apenas a ideologia dominante - do intelectual de fato, isto é, aquele que toma consciência de sua própria contradição: como funcionário da superestrutura situa-se na particularidade, mas seu saber é universal, por isso torna-se a própria contestação dos particularismos e não pode contestá-los sem contestar a si mesmo.

Foucault, por sua vez, destaca que o intelectual de 'esquerda' foi durante muito tempo reconhecido como o dono da verdade e da justiça, ele era um pouco "a consciência de todos" (FOUCAULT, 1999: 8), por isso podia ser caracterizado como "universal", derivado do jurista-notável, tendo sua expressão mais concreta no escritor. Entretanto, mais recentemente, 
passou a atuar em setores determinados, em pontos precisos, dando origem à figura do intelectual "específico", derivado do cientista-perito.

Bobbio chama a atenção para o fato de que o termo possui uma acepção ampla, referindo-se a quem não realiza trabalho manual, e uma acepção restrita, que compreende somente os "grandes intelectuais" (BOBBBIO, 1997: 71). Uma acepção intermediária, mais conveniente segundo os propósitos desse autor, deriva da relação entre política e cultura que, por sua vez, dá origem a dois tipos relevantes de intelectuais: os ideólogos e os expertos. Os primeiros são aqueles que fornecem os "princípios-guia" - concepções de mundo, valores, ideais, idéias gerais sobre os objetivos a perseguir - que fundamentam o agir político; os segundos são os portadores dos conhecimentos-meio, ou seja, os conhecimentos técnicos, específicos, indispensáveis para resolver problemas.

Beatriz Sarlo contrapõe os especialistas, os quais dominam um campo de saberes ou técnicas, aos intelectuais à moda antiga - artista, filósofo, pensador. A figura destes últimos entrou em ocaso embora suas funções continuem a ser reclamadas, enquanto os primeiros acreditam que a técnica é neutra e que seu saber pode isentar-se de ideologias ou interesses. O técnico reivindica a neutralidade valorativa, o intelectual a rejeita.

Eduardo Portella, circunscrevendo-se à realidade brasileira, prefere duvidar da própria designação 'intelectual' e apontar as etapas de desintelectualização de um projeto cultural brasileiro: primeiro havia a figura de letrado - desde o beletrista até o humanista, "todos eles servidores de um saber carregado de certezas" -; em segundo lugar surgiu o especialista - aquele que 'funcionaliza' os saberes universais -; e, finalmente, impôsse o tecnocrata - "o portador de um saber cada vez mais dominador e excludente." (PORTELLA; 1983: 19) 
Por fim, Marco Aurélio Nogueira, embora retome a distinção de Bobbio entre ideólogos e expertos, nomeia os intelectuais como "inventores do futuro". Alguns autores, sem adotar precisamente uma tipologia, delimitam o uso da palavra, como faz por exemplo Todorov, empregando-a em relação ao sábio ou ao artista que não se contenta em fazer ciência ou em criar obras de arte, porém "se sente mais preocupado com o bem público, com os valores da sociedade onde vive e participa dos debates que dizem respeito a estes valores" (TODOROV, 1999: 141); outros autores usam expressões significativas para referirse à categoria: Paul Nisan, em oposição a Benda, denomina de "cães de guarda" aqueles que, alegando estar acima de todas as classes, colocam-se ao lado do poder. Edward Said, por outro lado, buscando destacar o papel que atribui aos intelectuais - opor-se ao status quo - chama-os de franco-atiradores. E, resumindo suas conjecturas a respeito do desvanecimento crescente da influência dos intelectuais, Bernard-Henri Lévy indaga:

"Será preciso escrever, nos dicionários do ano 2000:
'Intelectual, substantivo de dois gêneros, categoria
social e cultural nascida em Paris no momento do caso
Dreyfus, morta em Paris no final do século XX;
aparentemente não sobreviveu ao declínio do
Universal'?" (LÉVY, 1998: 8)

Esse breve panorama, embora demonstre concepções diferentes em torno do termo discutido, não chega a revelar nenhuma oposição radical de idéias; na verdade, há um fio condutor que subjaz aos diversos posicionamentos. O ponto indiscutível é que o intelectual detém um saber, ele possui conhecimentos que, ademais de habilitá-lo profissionalmente, podem capacitá-lo a exercer uma determinada função, a desempenhar um determinado papel não necessariamente 
restrito à sua profissão, ao trabalho exercido em troca de remuneração. Ou seja, há uma questão que é a da formação acadêmica / profissão adquirida e exercida - o saber específico, o domínio de técnicas - e, então, estamos no âmbito da acepção ampla de intelectual; e há a questão, essa sim polêmica, que se refere à aplicação do conhecimento, ou mesmo da própria atividade - cargo ou emprego - em uma esfera mais abrangente e, nesse caso, utilizamos a acepção mais restrita e chegamos ao intelectual de fato. Naturalmente, o uso desse conhecimento além da dimensão profissional terá seus princípios norteadores, objetivos definidos e meios pelos quais se realiza publicamente e é um fazer caracterizado pela perspectiva política que possui.

Esse fio condutor parece tornar desnecessária a oposição entre ideólogos e expertos, pois o intelectual de fato, ainda que um experto profissionalmente, trabalha no campo das idéias, da reflexão, da análise crítica. Por outro lado, o que parece ser realmente insuperável é a contradição, talvez a razão de ser do intelectual. Se ele acredita na igualdade de todos os homens, e deve acreditar para que se justifique o seu papel, convive com a desigualdade entre o privilégio do conhecimento que adquiriu, da profissão que exerce, do cargo que ocupa e a impossibilidade de acesso ao conhecimento por parte de uma grande parcela da população, principalmente nos países subdesenvolvidos. Sendo originário da classe burguesa, não pode assimilar nem tão pouco reproduzir a ideologia burguesa, já que tal procedimento também contraria o princípio de igualdade. Sendo procedente da classe trabalhadora, o saber que adquire não só desvela a realidade onde está inserido, colocando-o num outro patamar de compreensão e possibilitando-lhe uma outra visão de mundo, como também propicia o acesso a uma profissão qualificada e por isso mais bem remunerada. Além disso, os ambientes que passa a freqüentar (bibliotecas, 
exposições, teatro, cinema, etc.), os debates e discussões dos quais deve participar (congressos, conferências, etc), as associações as quais se filia (sindicatos, conselhos regionais, clubes, etc.), em razão da necessidade de profissionalizar-se, de saber sempre mais e de renovar os conhecimentos que já possui, colocam-no em um outro meio, que já não é mais o da classe da qual provém.

Segundo Sartre, o intelectual só pode compreender a sociedade onde vive se adotar o ponto de vista dos desfavorecidos (SARTRE, 1994: 42), entretanto, justamente pelo que acaba de ser exposto, torna-se difícil estabelecer os parâmetros desse ponto de vista. A mobilidade social, o espaço transterritorial de que fala Eduardo Portella (PORTELLA, 1983: 22), é então o que pode garantir a amplitude do olhar, a diversidade de ângulos de estudo, a variedade de argumentos e estratégias de exame. Sua conduta deveria então se pautar pelo modelo ideal que Bobbio propõe: participar das lutas políticas e sociais de seu tempo, de modo a não se alienar, mas ao mesmo. tempo manter uma distância crítica "que o impeça de se identificar. completamente com uma parte até ficar ligado por inteiro a uma palavra de ordem" (BOBBIO, 1997: 79).

O desafio será sempre o de não perder de vista os valores, ou a ética, do papel que é convocado a desempenhar. Ética que deriva do respeito às necessidades essenciais do ser humano: viver plena e dignamente, em um ambiente onde não só esteja garantido o acesso às condições materiais de existência, como também estejam asseguradas a liberdade e a justiça.

Norteado por esses princípios, o papel do intelectual é discutir, esclarecer e denunciar o que impede a plenitude da vida humana. Se vivemos num mundo injusto e desigual, desde as relações cotidianas até as de âmbito internacional, cabe a ele estar atento às iniciativas que desrespeitam os direitos 
humanos, das mais restritas - institucionais, comunitárias - às mais amplas - governamentais, nos seus diversos níveis. Seu papel se desdobra em muitas funções, relacionadas ou. não à sua profissão, que se revelam sempre publicamente, pois não há sentido no seu fazer se não ecoar e atingir o alvo ao qual se destina. Cabe a ele, então, dentre muitas outras tarefas, debater as questões que inquietam a sociedade e contribuir na busca de soluções para os problemas, refletir sobre as grandes contendas e, em alguns momentos, iluminá-las, decodificar a linguagem muitas vezes cifrada dos discursos do poder e das medidas governamentais, mediar situações delicadas que envolvem o bem comum, identificar e desvelar as escamoteações tão freqüentes em projetos que envolvem a coletividade, etc.

Essas são, sem dúvida, tarefas difíceis. Requerem não só fôlego e disposição, mas também equilíbrio e sensatez pois, como observa Said, não há regras que definam, que pré-estabeleçam o que o intelectual tem de dizer ou fazer (SAID, 1996: 15). Por outro lado, é a sua habilidade de intervir no momento certo e de saber a medida justa de sua palavra e de seu gesto que o ajuda a projetar-se, a ser reconhecido e ouvido como voz abalizada. Ele não se faz da noite para o dia, vai-se formando aos poucos, no calor das discussões, nos consensos e dissensos do cotidiano das relações interpessoais, revelando-se através da consonância entre a teoria e a prática: se o seu agir contraria os princípios que defende, torna-se uma farsa. Não é possível ser democrático no discurso e autoritário na ação. Assim como não se admite que condene o preconceito, mas discrimine quem quer que seja. Daí a necessidade da autocrítica constante e de uma certa dose de humildade para reconhecer seus limites e não se deixar seduzir pelas glórias conquistadas. Além disso, deve buscar imunizar-se contra a tentação que o poder exerce. Quanto mais próximo da classe dirigente, maiores as chances de 
ser cooptado e aderir a uma "palavra de ordem" que contraria o interesse coletivo.

Aliás, quando o intelectual ocupa um cargo público, costuma ser problemática a sua relação com o poder. Nesse sentido, é iluminadora a argumentação de Marilena Chauí. Segundo a pensadora brasileira, a lógica da ação política tem duas características principais: ela se realiza num tempo muito veloz, sem que haja possibilidade de reflexão e impõe uma situação perversa, pois aquele que propõe a ação não é quem a realiza e aquele que propõe e realiza a ação não tem o controle sobre os resultados dessa ação. O processo burocrático intermediário entre a proposta e a sua concretização "rouba dos agentes o poder sobre sua própria proposta e sobre sua própria ação" (CHAUí, 2000: 54). O intelectual tem a ilusão de que detém o poder, mas não o detém. A situação se complica ainda mais quando ele acredita na sua autonomia e acha que pode realizar uma política de esquerda "com um sistema burocrático administrativo montado pela classe dominante". A lógica da "vida intelectual verdadeira" é outra: a reflexão tem o seu próprio tempo; além disso, "o pensador é o senhor das suas idéias e do seu pensamento do começo ao fim do processo" (p. 54). Por isso ele é capaz de comprometerse politicamente, o que é diferente de estar no poder.

\section{O intelectual na América Latina}

$\mathrm{Na}$ opinião de Foucault, a partir da Segunda Guerra Mundial, desenvolve-se a figura do intelectual "específico", o "cientista absoluto" cuja função e prestígio decorrem de um conhecimento que pode favorecer ou eliminar definitivamente a vida. A atenção desloca-se do "grande escritor", cantor da eternidade, para o "estrategista da vida e da morte"(FOUCAULT, 1999: 11). Obviamente, essa afirmação remete ao reordenamento 
político-ideológico que se engendrou a partir de 1945 sob a hegemonia de dois grandes blocos - Estados Unidos $\mathrm{x}$. União Soviética - configurando o que se chamou de "Guerra Fria" e determinando uma concentração de esforços e saberes com o objetivo de desenvolver armas cada vez mais sofisticadas e poderosas e ao mesmo tempo delinear estratégias de defesa e controle das regiões vulneráveis do planeta. Embora ciente de que essa ressalva por si só contextualiza o parecer de Foucault, não havendo talvez sentido em cogitar sobre sua validade para a realidade latino-americana, tomo a opinião do autor como contraponto para uma reflexão sobre um caso particular: a função do intelectual latino-americano. Para isso, vejamos algumas considerações do sociólogo mexicano Jorge Castañeda, retiradas do capítulo "Troca de guarda: dos intelectuais à base", de seu livro Utopia desarmada (1994), no qual ele busca descrever a trajetória da esquerda latino-americana, apontando os conflitos e as perspectivas que se vislumbram neste final de milênio e situando os intelectuais dentro desse panorama ${ }^{1}$.

Primeiramente, afirma o autor que muitos indivíduos dentre eles, escritores: Gabriel García Márquez, Carlos Fuentes, Pablo Neruda...; historiadores: Eduardo Galeano...; compositores e cantores: Chico Buarque...; diretores de jornais e revistas, editores e tradutores - "contribuem para fazer da esquerda intelectual latino-americana um caso à parte" (CASTAÑEDA, 1994: 152-3). Na América Latina, o alcance do termo "intelectuais" é muito amplo, pois são muito diversas as atividades daqueles a quem a palavra está associada.

\footnotetext{
' É necessário ressaltar que a exposição do autor é muito mais pormenorizada do que as idéias apresentadas aqui. Limito-me a retomar apenas algumas de suas principais observações.
} 
Observa em seguida que desde a independência e ao longo do século XIX os intelectuais ocuparam um lugar decisivo em muitas sociedades, participando ativamente em movimentos importantes, contribuindo precipuamente na tarefa de construção de uma identidade nacional ${ }^{2}$ :

Guardiães da consciência nacional, críticos sempre cobrando maior responsabilidade, baluartes de princípios e da retidão, durante quase cinco séculos os intelectúais latino-americanos, com seus escritos, lições, discursos e outras atividades, substituíram muitas instituiçōes e atores sociais. (CASTAÑEDA, 1994: 153)

No decorrer do século XX, continuaram se destacando em revoluções e reformas, opondo-se a golpes militares e ditaduras, atuando na educação, na cultura e nos meios de comunicação. Nos anos 70 e 80 , em meio a um cenário turbulento de perseguições e torturas, permaneceram na linha de frente, denunciando, resistindo, criticando. Sua atuação não deixou de ser significativa mesmo durante a transição para regimes menos autoritários, pois acompanharam a passagem para o governo civil, o estabelecimento das instituições democráticas, a estruturação de partidos políticos, além de lutarem pelo respeito aos direitos humanos. Estiveram presentes em debates comuns a todo continente - por exemplo, a intervenção dos Estados Unidos na América Central e a questão da dívida externa. No Brasil, personalidades como Florestan Fernandes, Fernando Henrique Cardoso e Celso Furtado colaboraram para o processo de redemocratização. $\mathrm{Na}$

${ }^{2} \mathrm{O}$ autor destaca Domingos Faustino Sarmiento, na Argentina; Rui Barbosa, no Brasil; José Martí, em Cuba; Valentín Gómez Farías e Ricardo Flores Magón, no México. 
Argentina, o Presidente Alfonsín delegou a uma comissão liderada pelo romancista Ernesto Sábato a tarefa de revisar o passado. No Peru, o famoso escritor Mario Vargas. Llosa candidatou-se à Presidência em 1990.

Segundo Castañeda, uma explicação para o realce da função dos intelectuais na América Latina está no papel de intermediários que desempenharam, ora entre a América Latina e o resto do mundo ${ }^{3}$, ora entre um Estado forte e uma sociedade civil fraca; eles atuaram preenchendo lacunas, substituindo alguém ou alguma coisa e, ainda que uma série de notáveis pensadores de direita tenha exercido uma verdadeira influência no continente, muitos dentre os mais famosos "situaram-se à esquerda do espectro político" (CASTAÑEDA, 1994: 158) e foram convertidos em interlocutores pelos governos locais e externos.

A intelligentsia latino-americana teve ainda papel proeminente nos acontecimentos que desembocaram, a partir dos anos 80 , na explosão da idéia de 'sociedade civil' e no fortalecimento dos 'movimentos populares', das 'organizações sociais ou de base', das 'organizações não governamentais', etc., mas ao mesmo tempo vai declinando progressivamente seu protagonismo: é a "troca de guarda" e a base vai aos poucos preenchendo os lugares antes ocupados pelos intelectuais (CASTAÑEDA, 1994: 169-70).

As assertivas de Castañeda apontam para o papel singular que tiveram os intelectuais em nosso continente, nos seus 500

\footnotetext{
${ }^{3}$ De acordo com o autor, foram eles que estabeleceram as pontes entre a defasada realidade latino-americana e a do resto do mundo. "Os intelectuais se puseram a viajar pelo mundo em busca de ideologias que estivessem à venda, e as assimilaram, embrulharam e mandaram a seus paises de origem para consumo local" (p. 155). Os efeitos nem sempre foram positivos: embora a discussão sobre a internacionalização dos intelectuais latino-americanos não seja nova, análises mais recentes apontam uma crescente submissão da intelligentsia do continente ao gosto do público internacional.
} 
anos de história oficial; os nomes que mais se destacaram, principalmente na área das letras, estiveram (ou ainda estão?) de algum modo associados aos fatos históricos de maior repercussão; seu fazer artístico vincula-se via de regra ao fazer político-histórico (um fazer "híbriclo"?). Frei Bartolomé de Las Casas (embora fosse espanhol) e sua tentativa de contar a história da conquista sob a perspectiva dos oprimidos - à parte a idealização que também faz do índio e a defesa de um processo de assimilação não-violento - talvez tenha inaugurado a atuação intelectual comprometida com a denúncia e a transformação.

Percebe-se melhor esse tipo de atuação "engajada" no século XVIII, quando o ideário ilustrado vai gradätivamente permeando não só o pensamento político e econômico como também os campos das ciências naturais e da literatura, e germinam os movimentos pela libertação do continente de suas metrópoles colonizadoras.

Os poetas se deixam contagiar pelo sentimento nativista $\mathrm{e}$ seus textos começam a evocar as belezas e singularidades do Novo Mundo: o poema Rusticatio mexicana (1781) do guatematelco Rafael Landívar (1731-1793) é um texto inaugural dessa literatura que, no século XIX, estará cada vez mais imbuída de americanismo. As Academias brasileiras (ou brasílicas), por consagrar atenção às coisas do Brasil, também reforçaram o nativismo e contribuíram "para o despertar do sentimento nacional" (CANDIDO, 1981: 79). Além disso, muitos escritores fizeram mais que produzir textos impregnados de espírito de nacionalidade, participando de movimentos emancipadores como é o caso dos poetas inconfidentes brasileiros Tomás Antônio Gonzaga e Cláudio Manuel da Costa, dos chamados escritores "proscritos" da Argentina, do cubano José Martí ou aderindo a outras lutas, como os republicanos e abolicionistas. 
No século XIX, a independência política constituiu um marco fundamental na história da América Latina e, uma vez alcançada a emancipação, impunha-se a tarefa de organizar as novas nações, de dar-lhes um contorno e um sentido próprios - um desafio que dependia tanto da re-estruturação politicoadministrativa e socio-econômica como da criação de uma nova mentalidade. Ou seja, a independência política supunha também uma emancipação das idéias, que se concretizaria sobretudo por meio de uma originalidade literária capaz de constituir um marco conceitual, possibilitando assim a consolidação da consciência americana. E os intelectuais tomaram para si a missão de delinear o contorno das jovens nações, resgatando suas peculiaridades e contribuindo para a construção de suas identidades.

No século XIX, então, surge uma literatura empenhada em fortalecer o sentimento americano e exaltar a pátria, desentranhando suas especificidades: "Todos cantam sua terra, / Também vou cantar a minha" são os versos de Casimiro de Abreu ilustrando as responsabilidades que assumiram os escritores da época de "pintar" com palavras a sua terra, prestando assim seu tributo ao nacionalismo. Sendo assim, o Romantismo foi, mais que uma escola literária, uma tendência aglutinadora de esforços, marcando um empenho de construir, entender, explicar, enfim, definir a Pátria (brasileira, argentina, mexicana... latino-americana) positivamente.

Em fins do século XIX e princípios do XX, o americanismo, antes formulado como valorização do que era característico do Novo Mundo, adquire uma perspectiva unificadora, presente nas visões de conjunto da realidade latino-americana, idealizadas por Carlos Octavio Bunge ("Nuestra América"), Manuel Ugarte ("Patria Grande") e Pedro Henríquez Ureña ("Magna Patria"), dentre outros. Essa perspectiva se materializou, pelo menos em 
parte, através de jornais com a participação de colaboradores de distintos pontos do continente ( $L a$ Prensa - 1869; La Nación - 1871) e de algumas revistas que se propuseram a promover um intercâmbio (que já era ensaiado por meio de encontros e correspondências) entre os intelectuais de diversos países, veiculando textos de tendências e gêneros variados, em português, espanhol e, alguns, em francês. Nelas, circularam as idéias de alguns dos nomes mais conhecidos do continente como: José Enrique Rodó, Rubén Darío (diretor de Mundial Magazine), García Calderón, Alfonso Reyes, José Asunción Silva, José Santos Chocano, José Veríssimo, Euclides da Cunha, etc. Os propósitos eram, como já foi dito, o intercâmbio e a integração continentais.

Durante o século XX outras vozes colaboraram no esboço de delinear o perfil de "Nuestra América", buscando entendê-la não apenas como uma comunidade nacional ou regional ou cultural, resultado de um conjunto natural exótico e de uma língua oficial, mas também como "el producto y la producción, precisamente, de una comunidad imaginada que actúa a nivel ideológico y afectivo sobre aquellos individuos que se sienten parte de ella." (ACHUGAR, 1994: 637)

Esse esforço de compreender e explicar o continente atravessou o século e caminhou paralelo a uma necessidade ainda não plenamente satisfeita - de legitimar seu discurso polifônico, de marcar sua identidade multicultural e, enfim, afirmar sua soberania ${ }^{4}$.

"Serve de ilustração a reportagem do jornal La Nación de 11 de abril de 1999, cujo título é "Los intelectuales, desconcertados", em que são destacados alguns exemplos de "viva intelectualidad": José Ingenieros - "sembró estímulos para una concepción idealista de la vida"; Ezequiel Martínez Estrada - "su obra reflejó una constante preocupación por el país"; Victoria Ocampo - "fue el símbolo de la cultura vernácula"; Ernesto Sábato - "se ha ocupado durante años del hombre envuelto en la crisis de nuestro tiempo". No Brasil, e em outros países da América Latina, poderíamos certamente destacar outros tantos exemplos. 
Buscou-se a legitimação do discurso através de uma literatura que não fosse simplesmente tradução do espírito nacional, mesmo porque "Si fosse nacional só o que é amerindio, também os italianos não podiam empregar o órgão que é egipcio, o violino que é árabe [...]" como observou em tom jocoso Mário de Andrade (1962: 15), do mesmo modo que Borges, posteriormente, referiu-se a uma curiosa confirmação de que "lo verdaderamente nativo suele y puede prescindir del color local": o fato de que no Alcorão, livro árabe por excelência, não há camelos (BORGES, 1997: 270). Entretanto, mesmo tendo Oswald de Andrade sugerido em seu Manifesto Antropófago uma saudável deglutição de influências - Tupy, or not tupy that is the question -, acreditanto que isso não poderia ser um impedimento para uma literatura autônoma, a questão das influências permaneceu por longo tempo gerando um certo mal-estar entre os escritores latino-americanos. Devido a esse mal-estar, Octavio Paz advertiu que as atitudes americanista e cosmopolita não deviam ser vistas como tendências separadas e inimigas, "mas como linhas que se entrecruzam, se bifurcam, se enlaçam e tornam a se separar, formando um tecido vivo. Esse tecido é nossa literatura" (PAZ, 1991: 177). De igual maneira, Silviano Santiago apontou a necessidade de substituir o método que privilegia o estudo das fontes e influências pois, a seu ver, o discurso do escritor latino-americano estaria situado em um "entre-lugar" já que ele, o escritor, debruçando-se sobre um modelo produtor, realizaria não uma tradução literal, mas "uma espécie de tradução global, de pastiche, de paródia, de digressão" (SAN'TIAGO, 2000: 23).

Nos últimos anos, entretanto, a preocupação com originalidade e autonomia perdeu, se não toda, pelo menos grande parte de sua razão de ser. Com a globalização, circulam os capitais e as mercadorias e também se compartilham as palavras 
e as idéias. Mas, se por um lado, somos levados a acreditar que os intelectuais da América Latina não precisam mais defender a legitimação de um discurso que, se não for global, poucas chances têm de sobreviver pois, como alerta Canclini, "un sector cada vez más extenso de la creación, la difusión y la recepción del arte se realiza hoy de un modo desterritorializado" (CANCLINI, 1995b: 11); por outro lado, percebe-se ainda um desprestígio do pensamento latino-americano frente, por exemplo, ao norte-americano. Embora o interesse pelo idioma castelhano e por questões latino-americanas tenha aumentado sensivelmente nos últimos anos, Beatriz Pastor identifica uma assimetria dentro do mundo acadêmico: o espanhol e a produção teórica nessa língua são considerados subalternos em relação a outras línguas minoritárias tais como o alemão e o francês (PASTOR, 1999: 66).

Igualmente, a identidade (nacional ou continental) tem sofrido o impacto da globalização; o debate das duas últimas décadas vem girando em torno do desmoronamento dos referenciais que permitiam a identificação com uma cultura, um espaço geográfico, com uma língua e com outros cidadãos, configurando o pertencimento a uma pátria e, conseqüentemente, a caracterização de uma nacionalidade. Hoje, estamos cientes de que as nações são comunidades imaginadas e narradas; são discursos construídos. Perdemos o chão sólido da pátria e ingressamos no terreno frágil da "aldeia global", do descentramento, da fragmentação das identidades. (HALL, 2000: 46)

No entanto, em se tratando de uma cogitada "identidade latino-americana", não seria mesmo possível construí-la, ou narrá-la, sobre uma homogeneidade que nunca existiu. E é a partir desse ângulo, formulado brilhantemente por Antonio Cornejo Polar, que, nos últimos anos, tem-se buscado exprimir as culturas que compartilham não só um espaço geográfico e 
socio-político - a América Latina - mas também uma história marcada pelos sucessivos processos de consquista / colonização/ dependência / neocolonização. Vejamos a proposição do autor peruano:

"Não se pode insistir em considerar a literatura latinoamericana como um sistema compacto e coerente e sua história como um processo linear e supressor; quando, na realidade, trata-se é de entender as rupturas de sua radical e desordenada heterogeneidade e os vários tempos que descompassadamente entretecem sua história." (CORNEJO POLAR, 2000: 117)

Desse modo, a discussão se desloca de uma concepção una, monolítica e harmônica de identidade, que desconsidera as diferenças e tenta excluir, por considerar dissonante segundo os critérios em voga, o popular, ou o mestiço, ou o índio, ou o pobre, ou o falante da língua "não-oficial", etc., para uma teoria que dê conta da reformulação multicultural das identidades, como propõe Canclini, depois de afirmar que:

"Las naciones y las etnias siguen existiendo. El problema clave no parece ser el riesgo de que las arrase la globalización, sino entender cómo se reconstituyen las identidades étnicas, regionales y nacionales en procesos de hibridación intercultural. Si concebimos las naciones como escenarios multideterminados, donde diversos sistemas simbólicos se intersectan e interpenetran, la pregunta es qué tipos de literatura, cine y televisión pueden narrar la heteterogeneidad y la coexistencia de varios códigos en un mismo grupo y hasta en un mismo sujeto." (CANCLINI, 1995b: 13)

Consideradas as questões relativas à legitimação do discurso e à identidade, resta ainda a que se refere à afirmação da soberania 
e nesse ponto passamos a trilhar um caminho pedregoso, pois parece que retornamos ao ponto de partida: não foi esse afinal o eixo em torno do qual se mobilizaram sempre os intelectuais? Não era a soberania que estava em jogo nas lutas pela independência? E mesmo quando se buscou através das Revistas a criação de "sólidos vínculos entre os isolados centros in'telectuais sulamericanos" não era essa uma tentativa de unir as vozes contra a posição já então privilegiada dos Estados Unidos na política pan-americana? Não foi a perspectiva integradora, retomada por Manuel Ugarte, Arturo Uslar Pietri, Leopoldo Zea, Ángel Rama, Antonio Candido, em momentos e lugares diferentes, uma maneira de unir forças contra as novas formas de colonização? Não será a recente procura de outros modos de narrar a heterogeneidade igualmente um modo de fazer prevalecer a integridade do continente?

Assistimos nas últimas décadas a mudanças significativas no cenário mundial: a queda do muro de Berlim, a desintegração do bloco comunista, a aceleração dos processos da globalização, o avanço do neoliberalismo, o afrouxamento das fronteiras e a compressão espaço-tempo que nos faz sentir o mundo menor e as distâncias mais curtas (HALL, 2000: 69), embora estejamos talvez cada vez mais distantes uns dos outros, etc. Na América Latina, e creio que em todo o Terceiro Mundo, essas transformações avassaladoras parecem aumentar ainda mais o descompasso: aqui tudo acontece depois - nem bem adentramos a modernidade e já se fala em pós-modernidade - e o desafio que se renova é o de acompanhar quem está na frente, queimando etapas e deixando à beira do caminho um número cada vez maior de excluídos.

O saldo positivo da globalização, se existe, está concentrado nas áreas mais desenvolvidas do planeta, de modo que os países subdesenvolvidos continuam carecendo de condições descentes de existência; a dependência se acentua e entraremos 
no século XXI vivendo a experiência da neocolonização: a periferia sob a égide dos consórcios transnacionais. Portanto, a soberania, a autonomia politico-socio-econômica ainda é o grande desafio, a meta ainda por alcançar e, se a figura do intelectual entrou em seu ocaso, algumas das tarefas que, pelo menos na América Latina, estiveram sob sua responsabilidade, ainda não foram realizadas.

Enquanto os "especialistas", ou "peritos", talvez estejam neste momento, em algum lugar do planeta, debruçados sobre estratégias de vida, ou de morte..., na periferia, os intelectuais "desconcertados" têm, como missão mais urgente, redefinir as estratégias que permitam renovar a utopia e resgatar a justiça e a igualdade de condições humanas de vida do limbo do descaso, do esquecimento ou simplesmente da omissão.

Tarefa que se atualiza das mais diversas maneiras, através de gestos concretos, propostas de ação, reflexões e as mais variadas textualidades. Eis alguns exemplos: Em almoço promovido por um candidato à Prefeitura do Rio, nas eleições de 2000 , intelectuais de várias gerações ouviram os planos do político em relação à cultura e indagaram sobre a distribuição de verbas para o setor; quando os garçons já recolhiam louças e talheres, Ferreira Gullar, que estivera calado durante todo o almoço, questionou: "Olha, está tudo muito bom, mas eu não quero fazer proposta nenhuma. Só quero saber o seguinte: quando é que alguém vai governar em favor do desamparado, do pobre, daquele que não tem vez?"5

A busca de alternativas que permitam combinar a circulação imediata, barata e fácil no mercado cultural hispano-falante com o acesso ao espaço de debate intelectual que o inglês domina atualmente e converter o campo do debate e das publicações

\footnotetext{
${ }^{5}$ Fonte: $O$ Globo, 03-09-00.
} 
do luso / hispano-americanismo em um campo realmente bilíngüe, como sugere Beatriz Pastor: uma política coerente e eficaz de tradução que viabilizasse traduções ao inglês e ao espanhol e garantisse a circulação imediata e constante do pensamento sobre a América Latina que se produz nas duas / [três] línguas (PASTOR, 1999: 75).

Os retratos da violência colombiana pintados por Fernando Botero, dentre eles: "A morte de Pablo Escobar", "Masacre de mejor Esquina", "Carro-Bomba". Um tipo de comprometimento com a realidade que se depreende da explicação de Botero: "A violência começou a estar na minha cabeça e senti um dia que tinha que pintar, fazer uma declaração do horror que sentia ante a esse panorama do país." ${ }^{\circ}$

Aa defesa de estratégias de integração e intercâmbio, já que, como alerta Antonio Candido: "Estabelecer vínculos entre os intelectuais da América Latina é contribuir para diversas libertações." (CANDIDO, 1999: 263)

Os relatos que narram o continente ou pequenas partes dele, que recompõem sua realidade, reconstroem o cruzamento de culturas, expõem as fissuras e reinventam os sonhos.

É pouco talvez, porém melhor do que o vazio, a ausência de expectativas. Não esperamos mais revoluções; não haverá mais ouvintes para discursos inflamados que conclamem a organização das massas e a tomada do poder. O vocábulo conscientização voltou ao estado de dicionário, não faz mais parte da rotina diária, não é mais uma tarefa; a função do intelectual não é mais esclarecer, desvelar. Estabeleceu-se a democracia, embora a dominação continue se alastrando sutilmente, minando as formas mais criativas de existência. Mas tudo isso acontece tão... tão... subterraneamente! Contudo, ao

\footnotetext{
"Fonte: $O$ Globo, 20-08-00.
} 
intelectual resta a palavra que, através da tela, da escultura, da música, da história, da poesia, do filme, da novela, ... também, subterraneamente, há de um dia minar as formas de poder que reproduzem a desigualdade!

Pode-se perguntar sobre as possibilidades do fazer intelectual em um mundo regido pela globalização, fragmentado, quando parece não ser necessário resgatar o passado, não há sentido para o presente e o futuro, mais que nunca, carece de significado. Quais são, hoje, as vozes que ousam falar verdades, apontar equívocos, desvelar a realidade? E, por outro lado, quem está interessado em ouvir verdades e ver a realidade com lentes transparentes? Se parece não haver mais um lugar apropriado para o intelectual, se a razão de ser de sua atividade vacila errante no vazio de um mundo sem sentido e a sua voz se perde em meio à sedução das redes globais, do mesmo modo parece não haver mais quem esteja disposto a indagar e buscar respostas. Contudo, seria um erro reduzir a discussão a esses termos: os intelectuais se calam porque não há quem os queira ouvir. Mesmo se, premidos pela força dos acontecimentos das últimas décadas, reconhecemos que não haverá uma transformação mágica do Estado, que o comunismo foi mais uma rota alternativa para o inferno do que uma solução milagrosa para a desigualdade e que a crença em uma revolução liderada pelo proletariado foi uma quimera, mesmo assim ainda não é o tempo da clandestinidade que possivelmente convenha a alguns (LÉVY, 1988: 102). O desafio talvez seja o de reformular as estratégias de intervenção e não descartar os meios disponíveis - a televisão, os jornais, o espaço virtual - e, ao invés de sucumbir diante do poder e da sedução das indústrias culturais que, segundo Canclini, alteraram a configuração dos campos simbólicos, tornando cada vez mais problemática a autonomia da arte e, por que não dizer, do pensamento crítico, 
buscar redefinir os modos pelos quais podemos "refazer conjuntamente o papel do Estado e da sociedade civil" (CANCLINI, 1995: 189).

Pode-se alegar que a rede global tornou-se um labirinto do qual é difícil encontrar a saída, mas exatamente devido ao caos instalado, precisa-se da figura do intelectual, "da sua disposição crítica e sua capacidade de forjar projetos e utopias direcionadas para a justiça social e a emancipação de todos." (NOGUEIRA, 1999: 14)

Na América Latina foi sempre complicado separar a tarefa intelectual do comprometimento político e da missão de denunciar as situações injustas. O fato de receber o Prêmio Nobel de Literatura, por exemplo, fez com que García Márquez pronunciasse as seguintes palavras:

"Me atrevo a pensar, que es esta realidad descomunal, y no sólo su expresión literaria, la que este año ha merecido la atención de la Academia Sueca de las Letras. Una realidad que no es la del papel, sino que vive con nosotros y determina cada instante de nuestras incontables muertes cotidianas, y que sustenta un manantial de creación insaciable, pleno de desdicha y de belleza, del cual este colombiano errante y nostálgico no es más que una cifra más señalada por la suerte. Poetas y mendigos, músicos y profetas, guerreros y malandrines, todas las criaturas de aquella realidad desaforada hemos tenido que pedirle muy poco a la imaginación, porque el desafío mayor para nosotros ha sido la isuficiencia de los recursos convencionales para hacer creíble nuestra vida. Este es, amigos, el nudo de nuestra soledad." ${ }^{7}$

\footnotetext{
7 Este é um fragmento da "Conferencia Nobel 1982: La Soledad de América Latina". (SKIRIUS, 1994: 469-73)
} 
Este continente talvez seja um "entre-lugar" da existência: não estar em nenhum lugar e em todos ao mesmo tempo vacilar ao escrever o próprio nome, tremulamente desenhar a assinatura para, logo depois, teclar o número de um candidato na urna eletrônica; atender a uma chamada de celular dentro de um ônibus que pode ser assaltado na próxima esquina; desfrutar temerosamente de uma cobertura em um prédio de luxo de um bairro rico porque sempre há a possibilidade de um assalto ou um seqüestro. Tentar entender o outdoor que adverte "Sorria. Você chegou à Barra" (área nobre do Rio de Janeiro) tendo ao fundo uma orquestra de barracos desalinhados que escancaram a pobreza absoluta e fazem da bala perdida um risco iminente.

É no interstício dessa "realidade desaforada" onde se instalam os dilemas e desafios cujas respostas ainda dependen daqueles intelectuais que não abdicaram de sua responsabilidade.

Resumen: El intelectual detiene un saber, posee conocimientos que, además de autorizarlo profesionalmente, pueden babilitarlo a ejercer determinada función no siempre restricta a su profesión. Su reto será el de tener presentes los valores - la ética - del papel que debe desempeñar. Ética que deriva del respeto a las necesidades esenciales del ser bumano: vivir de modo pleno $y$ digno, en un ambiente donde se garantice el acceso a las condiciones materiales de existencia y se aseguren la libertad y la justicia. Anclado en dichos principios, el intelectual en América Latina se ba dedicado a discutir, aclarar y denunciar lo que impide la plenitud de la vida bumana. 


\section{Referências bibliográficas}

ACHUGAR, Hugo. "La hora americana o el discurso americanista de entreguerras". In: PIZARRO, Ana (Org.). América Latina: palavra, literatura e cultura. São Paulo: Memorial; Campinas: UNICAMP, 1994, v. 2.

ANDRADE, Mário de. "Ensaio sobre a música brasileira". In: ANDRADE, Mário. Obras completas. São Paulo: Martins, 1962, v. 6.

BOBBIO, Norberto. Os intelectuais e o poder: dúvidas e opções dos homens de cultura na sociedade contemporânea. São Paulo: UNESP, 1997.

BORGES, Jorge Luis. "El escritor argentino y la tradición". In: BORGES, Jorge Luis. Obras completas. Barcelona: Emecé, 1997. v. 1.

CANCLINI, Néstor García. Consumidores y ciudadanos. México: Grijalbo, 1995.

CANCLINI, Nestor García. Culturas bíbridas. São Paulo: EDUSP, 1998.

CANCLINI, Nestor García. Las industrias culturales en la integración latinoamericana. Buenos Aires: Eudeba, 1999.

CANCLINI, Nestor García. "Narrar la multiculturalidad". In: Revista de crítica literaria latinoamericana. Año XXI, $\mathrm{n}^{\circ} 42$. Lima-Berkeley, $2^{\circ}$ semestre de 1995.

CANDIDO, Antonio. "Conhecer, conviver, integrar: anotações muito pessoais". Em: Revista de crítica literaria latinoamericana. Año XXV, $\mathrm{n}^{\circ}$ 50. Lima-Hanover, $2^{\circ}$ semestre de 1999.

CANDIDO, Antonio. Formação da literatura brasileira: momentos decisivos. Ged. Belo Horizonte: Itatiaia, 1981, v. 1.

CASTAN̈EDA, Jorge G. Utopia desarmada: intrigas, dilemas e promessas da esquerda latino-americana. Trad. Eric Nepomuceno. São Paulo: Companhia das Letras, 1994.

CHAUÍ, Marilena. "A interrogação permanente de Marilena Chaúi". In: Cult. Ano 3, n 35 . São Paulo, junho de 2000. 
CORNEJO POLAR, Antonio. O condor voa. Literatura e cultura latinoamericanas. Trad. Ilka Valle de Carvalho. Minas Gerais: Ed. UFMG, 2000.

FOUCAULT, Michel. Microfísica do poder. 14ed. Rio de Janeiro: Graal,1999.

GRAMSCI, Antonio. Os intelectuais e a organização da cultura. 3ed. Rio de Janeiro: Civilização Brasileira, 1979.

HALL, Stuart. A identidade cultural na pós-modernidade. Trad. Tomaz. Tadeu da Silva e Guacira Lopes Louro. 4ed. Rio de Janeiro: DP\&A, 2000.

LÉVY, Bernard-Henri. Elogio dos intelectuais. Rio de Janeiro: Rocco, 1988.

LIBEDINSKY, Juana. "Los intelectuales, desconcertados". Buenos Aires, La Nación, 11 de abril de 1999.

NOGUEIRA, Marco Aurélio. "Inventores do futuro. Notas sobre os intelectuais, a política e a vida". In: Z. Revista eletrônica, 1999. http://acd.ufrj.br/z/ensaios.

PASTOR, Beatriz. "Realidades entreveradas y nuevo latinoamericanismo". In: Revista de crítica literaria latinoamericana. Año XXV, $\mathrm{n}^{\circ}$ 50. LimaHanover, $2^{\circ}$ semestre de 1999.

PAZ, Octavio. Convergências. Ensaios sobre arte e literatura. Rio de Janeiro: Rocco, 1991.

PORTELLA, Eduardo. O intelectual e o poder. Rio de Janeiro: Tempo Brasileiro, 1983.

SAID, Edward W. Representaciones del intelectual. Barcelona: Paidós, 1996.

SANTIAGO, Silviano. Uma literatura nos trópicos: ensaios sobre dependência cultural. 2 ed. Rio de Janeiro: Rocco, 2000.

SARLO, Beatriz. Cenas da vida pós-moderna. Trad. Sérgio Alcides. Rio de Janeiro: UFRJ, 1997. 
SARTRE, Jean-Paul. Em defesa dos intelectuais. São Paulo: Ática, 1994.

SKIRIUS, John (Comp.). El ensayo bispanoamericano del siglo XX. 3 ed. México: Fondo de Cultura Económica, 1994.

TODOROV, Tzvetan. O bomem desenraizado. Rio de Janeiro: Record, 1999. 